\title{
Retrospective Analysis of Clinicopathological Characteristics and Family History Data of Early-Onset Breast Cancer: A Single-Institutional Study of Hungarian Patients
}

\author{
Lilla Madaras • Zsuzsanna Baranyák • Janina Kulka • Attila Marcell Szász • \\ Attila Kovács • Phan Huong Lan • Borbála Székely • Magdolna Dank • Tibor Nagy • \\ Orsolya Kiss • László Harsányi • Tamás Barbai • István Kenessey • Anna Mária Tőkés
}

Received: 18 May 2012 / Accepted: 4 April 2013 / Published online: 26 May 2013

(C) Arányi Lajos Foundation 2013

\begin{abstract}
Patients at young age ( $\leq 35$ years) diagnosed with breast cancer $(\mathrm{BC})$ are considered to have poor prognosis. The aim of the present study was to retrospectively analyse clinicopathological characteristics and prognosis in a group of young BC patients. We included women diagnosed with invasive breast carcinoma younger than/or at the age of 35 years. Between 1999 and 2009, 107 women with early-
\end{abstract}

Lilla Madaras and Zsuzsanna Baranyák equal contribution.

Electronic supplementary material The online version of this article (doi:10.1007/s12253-013-9635-z) contains supplementary material, which is available to authorized users.

L. Madaras · J. Kulka • A. M. Szász • A. Kovács • P. H. Lan •

B. Székely $\cdot$ O. Kiss $\cdot$ T. Barbai $\cdot$ I. Kenessey

2nd Department of Pathology, Semmelweis University,

Budapest, Hungary

Z. Baranyák

Department of Surgery, Ministry of Defence State Health Centre, Budapest, Hungary

M. Dank

Oncotherapy Unit, Department of Diagnostic Radiology and

Oncotherapy, Semmelweis University, Budapest, Hungary

T. Nagy

Mezőgazdasági Biotechnológiai Kutatóközpont, Szent-Györgyi

Albert u. 4. Gödöllő, 2100 Magyarország, Budapest, Hungary

L. Harsányi

1st Department of Surgery, Semmelweis University, Budapest, Hungary

A. M. Tőkés $(\bowtie)$

2nd Department of Pathology, Semmelweis University,

Budapest, Hungary, MTA-SE Tumour Progression

Research Group, Ulloi ut 93,

1091 Budapest, Hungary

e-mail: ta@med.semmelweis-univ.hu onset $\mathrm{BC}$ were selected from the database of the 2nd Department of Pathology at Semmelweis University. For clinicopathological comparison, 55 women (36-45 years), 214 women (46-65 years), 110 women (66-75 years) and 58 women ( $76 \leq$ years) were also included in the analysis. Family history, clinicopathological and follow-up data were analysed. The tissue specimens were reviewed for histological type, nuclear grade, and estrogen receptor (ER), progesterone receptor (PgR), Ki67 and HER2 status (IHC4). The mean age in the study group was 31.6 years at the time of diagnosis. Histology showed a high incidence of grade III tumours in this group of patients $(67.9 \%)$, while only four cases $(3.8 \%)$ were considered grade I. According to the immunohistochemical results, $35.3 \%$ of the study cases were considered as Luminal B (LumB: either being higly proliferative or co-expressing HER2) and $33.3 \%$ as triple negative breast carcinomas (TNBC). The detailed questionnaire related to family history was completed and received in 49/107 cases (45.8\%). Analysis of these data revealed an affected family history of breast or ovarian carcinoma in first and second degree relatives in $51.0 \%$. A high proportion $(52.0 \%)$ of TNBC was observed among young women with a family history of the disease. Survival analysis of the 107 patients showed that 25 (23.3\%) women died until 31 December 2012. No significant difference in survival was detectable considering the regimen of systemic treatment ( $p=0.188)$. Regarding clinicopathological parameters, the immunophenotypes, grade, $\mathrm{pT}$ and $\mathrm{pN}$ values differred substantially between the age groups ( $p=0.001$, for all), and the shortest relapse-free survival was seen among the youngest $\mathrm{BC}$ patients. This analysis illustrates that breast cancer arising in young women is characterized by the presence of less favorable subtypes such as LumB and TNBC. The increased proportion of TNBC was especially remarquable in the 
group of patients presenting with family history of the disease. The fact that a high rate of death occured and no significant difference in OS were notable regarding the scheme of systemic therapies (neoadjuvant vs. adjuvant) highlight the necessity of the development of new treatment strategies.

Keywords Breast cancer $\cdot$ Early-onset $\cdot$ Family history

\section{Introduction}

Breast cancer is one of the most common cause of cancerrelated death among women worldwide. According to the Hungarian National Cancer Registry (GRID), 6807 women were diagnosed with breast cancer in 2007 [1]. Although, breast cancer is relatively uncommon in young women it is considered to be the most frequent cancer in women $<40$. It is generally accepted that up to $4 \%$ of breast cancer cases occur in women younger than 35 years $[2,3]$. In many studies age younger than 35 years is considered as an independent predictor of poor outcome and patients $<35$ 40 years at the time of diagnosis have been found to have a poorer prognosis compared with older patients, furthermore, multiple data have demonstrated that younger patients treated with breast carcinomas have a significantly higher rate of local recurrence compared with older patients $[4,5]$. The group of Hanna et al. found that young women with breast carcinomas have a higher risk of dying of the disease as compared to middle-aged breast cancer patients even if carcinomas are diagnosed early and patients receive stateof-the-art treatment [5]. These results could partly be explained by the fact that young women are diagnosed more often at advanced stages, present unfavorable tumour characteristics or have a family history of breast cancer [6-9]. In a very recent study of Lin et al. it is suggested that these cancers occurring at a very young age may be considered as a distinct disease entity [10]. Due to the relatively low frequency of breast carcinomas in women aged $\leq 35$ years there are few data on how risk factors predict breast cancer in younger women and the prognostic factors in this group have yet to be established. A proportion of breast carcinoma arising at young age are the so called pregnancy associated breast carcinomas (PABC). The incidence of breast cancer in pregnancy appears higher than previously reported with women over 35 being at greater risk [11]. In certain families it is clear that there is a predisposition to develop breast cancer inherited in an autosomal dominant way [12]. Previous studies have established that family history of the disease along with atypical ductal hyperplasia, or atypical lobular hyperplasia and carcinoma in situ (DCIS or LCIS) are important predictors of breast cancer risk [12]. The same study found that for women $\leq 35$ years a significant family history of breast cancer may be a stronger predictor for breast cancer development than the high risk lesions mentioned above [12]. The role of mutations in the tumour suppressor genes BRCA1 and BRCA2 has been extensively studied and it is considered that women who are carriers of these mutations present a high risk of developing breast cancer by the age of $50[13,14]$. Although, testing for BRCA1 and BRCA2 mutations is expensive, analysis of these genes has important implications for the clinical management of people carrying these mutations. Several algorythms that predict the likelihood of carrying BRCA1 and BRCA2 mutations are being currently used in clinical practice [15-17].

According to pathological parameters, young women are more likely to have high grade hormone receptor negative tumours with a high proliferation rate and lymphovascular invasion $[9,18,19]$. In the study of Lin et al. it is presented that for women $\leq 35$ years high Ki67 expression, TP53 mutations, ER negative status and HER2 overexpression were associated with shorter overall survival, and TP53 mutations, Ki67, HER2 overexpression are strong prognostic factors for these women [10].

The aim of the present study was to retrospectively evaluate clinicopathological characteristics and prognosis in a selected group of young Hungarian breast cancer patients $\leq 35$ years.

\section{Patients and Methods}

\section{Study Group}

In our study we included patients younger than or at the age of 35 diagnosed with invasive breast carcinoma (group nr. 1). During the period between 1999 and 2009107 women met these criteria altogether from the files of the 2nd Department of Pathology, Semmelweis University, Budapest, Hungary. Slides and blocks were identified from each of these patients, and clinicopathological and follow-up information were obtained. For comparison, 55 women (3645 years) (group nr. 2), 214 women (46-65 years) (group nr. 3), 110 women (66-75 years) (group nr. 4) and 58 women ( $76 \leq$ years) (group nr. 5) diagnosed with breast cancer were also included in the clinicopathological analysis. Those cases, which were screen-detected breast cancers were excluded from the study.

\section{Pathological Evaluation}

Specimens were reviewed for histological type, nuclear grade and were stained for ER, PgR, Ki67, HER2 immunohistochemistry (IHC), as described further on and presented in Table 1. Histological grading was performed according to 
Table 1 Source and dilutions of the four immunohistochemical markers analysed in this study

\begin{tabular}{ll}
\hline Antigen & Distributor, clone, dilution \\
\hline ER & Novocastra, 6F11 (1:200) \\
PgR & Novocastra, 312 (1:200) \\
HER2 & Novocastra, CB11 (1:150) \\
Ki-67 & DAKO, MIB1 (1:100) \\
\hline
\end{tabular}

the Nottingham grading system. Proxies of the molecular subtypes were determined by immunohistochemical stains of ER, PgR, HER2, Ki67 and HER2 FISH.

Immunohistochemical reactions (IHC) were performed with automated immunostainer system (Ventana ES, Ventana Medical Systems, Inc., Tucson, AZ, USA) according to the manufacturer's instructions using the antibodies given in Table 1. The immunohistochemical slides were evaluated by two investigators independently (JK and LM). ER and PgR statuses were given according to the Allred scoring system, Ki67 positivity was measured as the ratio of positive tumour cell nuclei in the tumour and HER2 IHC was evaluated according to the guidelines, on a $0-3$ scale standard protocol.

Fluorescent in situ hybridization (FISH) evaluation was performed by using HER2/CE17 Poseidon probes (KBI10735, Kreatech Diagnostics, Amsterdam, The Netherlands). FISH results were evaluated according to the standard protocol: non-amplified if the HER2/CE17 ratio was less than 1.8, equivocal if this ratio was between 1.8 and 2.2, and amplified if the HER2/CE17 ratio was over 2.2. When discordant with HER2 IHC, the FISH results were taken into consideration.

ER and/or PgR expressing tumours with lower than $20 \%$ Ki67 expression were considered luminal A (LumA). For ER and/or PgR and HER2 positive tumours and ER and/or PgR expressing tumours with more than or equal to $20 \%$ Ki67 index, luminal B subtype (LumB) was assigned. Triple negative breast cancers (TNBC) were ER, PgR, HER2 negative. The HER 2 overexpressing ( $3+$ by IHC) or $2+$ cases showing HER2 gene amplification by FISH and in the same time ER and PgR negative tumours were considered as the HER2+ subgroup.

\section{Family History}

A detailed questionnaire was composed and sent to the young breast cancer patients/affected families.

\section{Statistical Analysis}

The differences between the groups were analysed using chi-square test and the Kruskal-Wallis test with subsequent post-hoc method. Relapse-free survival analyses were performed using the Kaplan-Meier method. Overall survival was determined as the time period from initial diagnosis to the time of death. The comparison between survival functions for different strata was assessed with the log-rank test. Statistical significance was confirmed when $p$ values were $<$ 0.05. Statistical analysis was performed using Statistica 9.0 software (StatSoft, Tulsa, OK, USA) and SPSS 17 (SPSS Inc., Chicago, IL, USA).

\section{Results}

Clinicopathological Assessment Median age at the time of diagnosis in the early-onset age group was 31.64 years, the youngest patient being diagnosed with breast carcinoma at the age of 22. Histology showed a high incidence of grade III tumours in this group of patients (70 cases, $67.96 \%$ ), while only four cases $(3.88 \%)$ were considered grade I. In 29 cases $(28.16 \%)$ grade II cancer was diagnosed whereas in four cases $(3.73 \%)$ we have no data (cytology specimens only). According to the immunophenotypical results, which were available in 99 patients, 22 tumours were enrolled in LumA (22.22\%), 35 in LumB (35.35\%), 9 in HER2+ $(9.09 \%)$ and 33 in TNBC (33.33\%) subgroups.

The respective groups had a mean age at time of diagnosis as follows, $36-45$ years: $41.95,46-65$ years: $54.53,66-$ 75 years: 70.09 and over 76 years: 80.66 . We have compared the tumour characteristics of the women included in the study, shown in Table 2. Significant difference was detected in the comparison of the subtypes and grades between the early-onset breast tumours and the other age groups ( $p<0.001$ for all, Figs. 1 and 2, respectively). Pathological " $\mathrm{T}$ " and " $\mathrm{N}$ " status also differed but tumour size measured in mm's was similar in the overall population (Supplementary Figure 1).

Family History The detailed questionnaire related to family history was completed and received in 49 cases (45.79\%). Analysis of these data revealed positive family history of breast or ovarian carcinoma reported in first and second degree relatives in 25 cases $(51.02 \%)$. In 13 cases $(26.53 \%)$ no family history of breast or ovarian carcinoma was mentioned, whereas in 11 cases $(22.44 \%)$ other types of tumours were mentioned in first and second degree relatives. By accepting that the number of cases analysed is low, interesting results were found when comparing the group of patients with family history with the group of patients without family history of breast or ovarian carcinomas. An increased proportion ( $52 \%$ ) of TNBC was observed among younger women with a family history of the disease whereas in the group of patients without family history of breast and 
Table 2 Tumour characteristics of the 544 women included in the study

\begin{tabular}{|c|c|c|c|c|c|c|c|}
\hline Age group & & 1 & 2 & 3 & 4 & 5 & $\begin{array}{l}p \\
\text { (chi-sq.) }\end{array}$ \\
\hline Number of cases & & 107 & 55 & 214 & 110 & 58 & \\
\hline \multirow[t]{4}{*}{ Subtype } & $\begin{array}{l}L U M A \\
L U M B P r\end{array}$ & $\begin{array}{l}22.22 \% \\
20.20 \%\end{array}$ & $\begin{array}{r}70.00 \% \\
7.50 \%\end{array}$ & $\begin{array}{r}70.90 \% \\
6.72 \%\end{array}$ & $\begin{array}{r}73.33 \% \\
5.33 \%\end{array}$ & $\begin{array}{r}66.67 \% \\
9.52 \%\end{array}$ & \multirow[t]{4}{*}{0.001} \\
\hline & LUMB_H2 & $15.15 \%$ & $5.00 \%$ & $5.97 \%$ & $2.67 \%$ & $4.76 \%$ & \\
\hline & HER2 & $9.09 \%$ & $10.00 \%$ & $4.48 \%$ & $8.00 \%$ & $2.38 \%$ & \\
\hline & $T N B C$ & $33.33 \%$ & $7.50 \%$ & $11.94 \%$ & $10.67 \%$ & $16.67 \%$ & \\
\hline \multirow[t]{2}{*}{ Grade } & $\begin{array}{l}1 \\
2\end{array}$ & $\begin{array}{r}3.88 \% \\
28.16 \%\end{array}$ & $\begin{array}{l}29.41 \% \\
35.29 \%\end{array}$ & $\begin{array}{l}32.61 \% \\
44.57 \%\end{array}$ & $\begin{array}{l}32.65 \% \\
39.80 \%\end{array}$ & $\begin{array}{l}37.74 \% \\
41.51 \%\end{array}$ & \multirow[t]{2}{*}{0.001} \\
\hline & 3 & $67.96 \%$ & $35.29 \%$ & $22.83 \%$ & $27.55 \%$ & $20.75 \%$ & \\
\hline \multirow[t]{7}{*}{$\mathrm{T}$} & $\begin{array}{l}1 \\
2\end{array}$ & $\begin{array}{l}31.91 \% \\
39.36 \%\end{array}$ & $\begin{array}{l}10.74 \% \\
27.52 \%\end{array}$ & $\begin{array}{l}11.62 \% \\
29.33 \%\end{array}$ & $\begin{array}{l}13.52 \% \\
27.05 \%\end{array}$ & $\begin{array}{l}11.61 \% \\
27.10 \%\end{array}$ & \multirow[t]{7}{*}{0.001} \\
\hline & 3 & $2.13 \%$ & $30.20 \%$ & $29.52 \%$ & $28.11 \%$ & $28.39 \%$ & \\
\hline & 4 & $1.06 \%$ & $30.20 \%$ & $28.95 \%$ & $29.89 \%$ & $29.68 \%$ & \\
\hline & $y 0$ & $5.32 \%$ & $0.00 \%$ & $0.00 \%$ & $0.00 \%$ & $0.00 \%$ & \\
\hline & $y 1$ & $8.51 \%$ & $0.00 \%$ & $0.00 \%$ & $0.00 \%$ & $0.00 \%$ & \\
\hline & $y^{2}$ & $6.38 \%$ & $0.00 \%$ & $0.00 \%$ & $0.00 \%$ & $0.00 \%$ & \\
\hline & $y 3$ & $4.26 \%$ & $0.00 \%$ & $0.00 \%$ & $0.00 \%$ & $0.00 \%$ & \\
\hline \multirow[t]{8}{*}{$\mathrm{N}$} & 0 & $25.58 \%$ & $41.46 \%$ & $44.72 \%$ & $44.83 \%$ & $43.48 \%$ & \multirow[t]{8}{*}{0.001} \\
\hline & 1 & $27.91 \%$ & $51.22 \%$ & $51.22 \%$ & $46.55 \%$ & $52.17 \%$ & \\
\hline & 2 & $15.12 \%$ & $7.32 \%$ & $4.07 \%$ & $8.62 \%$ & $4.35 \%$ & \\
\hline & 3 & $3.49 \%$ & $0.00 \%$ & $0.00 \%$ & $0.00 \%$ & $0.00 \%$ & \\
\hline & $y 0$ & $13.95 \%$ & $0.00 \%$ & $0.00 \%$ & $0.00 \%$ & $0.00 \%$ & \\
\hline & $y 1$ & $6.98 \%$ & $0.00 \%$ & $0.00 \%$ & $0.00 \%$ & $0.00 \%$ & \\
\hline & $y^{2}$ & $4.65 \%$ & $0.00 \%$ & $0.00 \%$ & $0.00 \%$ & $0.00 \%$ & \\
\hline & y3 & $2.33 \%$ & $0.00 \%$ & $0.00 \%$ & $0.00 \%$ & $0.00 \%$ & \\
\hline
\end{tabular}
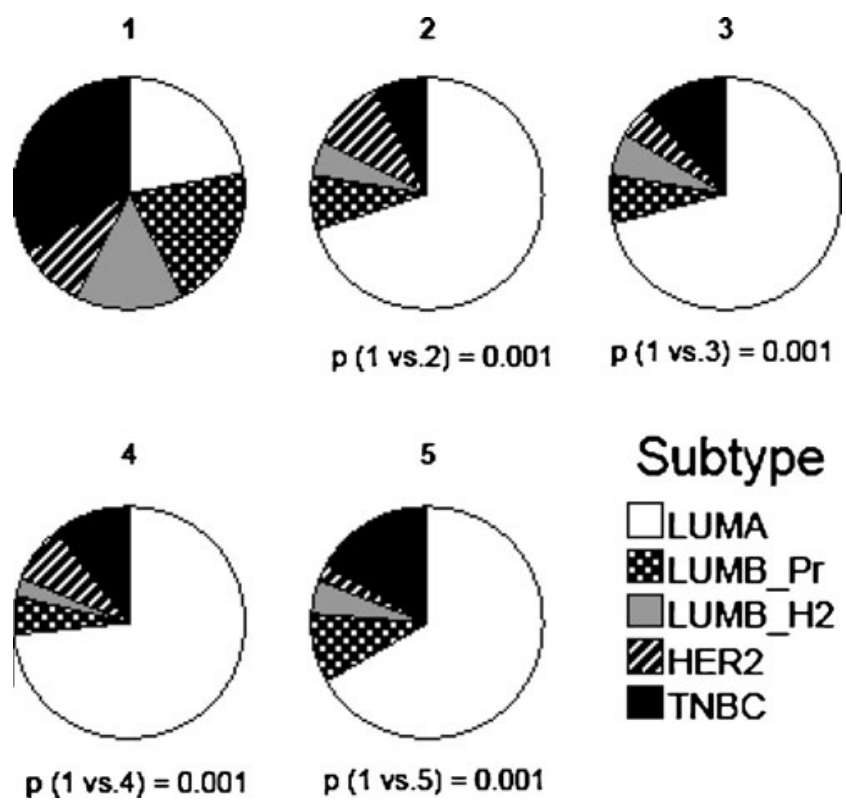

Fig. 1 Differences between the subtypes in the early-onset breast tumours and the other age groups
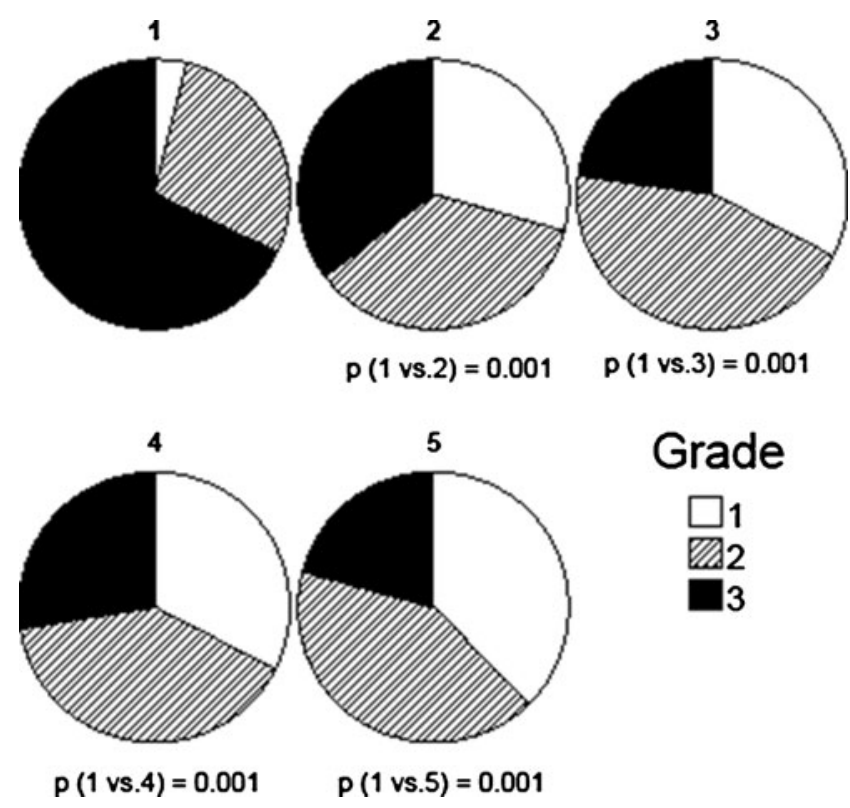

Grade

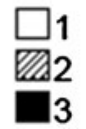

Fig. 2 Differences between the grades in the early-onset breast tumours and the other age groups 
ovarian carcinoma the LumA tumours were found in higher percentage $(46.15 \%)$.

Survival Analysis To assess the prognosis of all the age groups, the relapse-free survival using Kaplan-Meier analysis of the above mentioned 544 breast cancer patients was performed. The early-onset groups displayed the worse prognosis when compared to others (Fig. 3).

As of December 2012, 25 out of 107 (23.36\%) women in the young BC population died. Accepting that the number of cases with known family history was relatively low, we did not find significant association $(p=0.975)$ between OS and negative family history versus a family history of breast or ovarian carcinoma in first and second degree relatives (Fig. 4a). No statistically significant differences were observed ( $p=0.188$ ) when comparing OS in patients with negative family history and patients having a family history of other types of tumours (Fig. 4b). No significant differences in survival $(p=0.188)$ were detectable between the applied (neoadjuvant vs. adjuvant) chemotherapy (Fig. 4c).

When analysing the subtype of tumours in the group of patients who died ( $25 \mathrm{pts}$ ) we found that the highest number of deaths was observed in the LumB subgroup (36\%), followed by the TNBC subtypes (32\%), LumA types $(20 \%)$ and HER2+ cases (12\%).

Treatment data for the early onset breast cancer patients included in this study was available in 56 cases. Of these cases 24 patients $(22.42 \%)$ received neoadjuvant therapy whereas 32 patients $(29.90 \%)$ received adjuvant therapy. In 51 cases $(47.66 \%)$ no treatment data was available. No significant differences in survival were detectable between

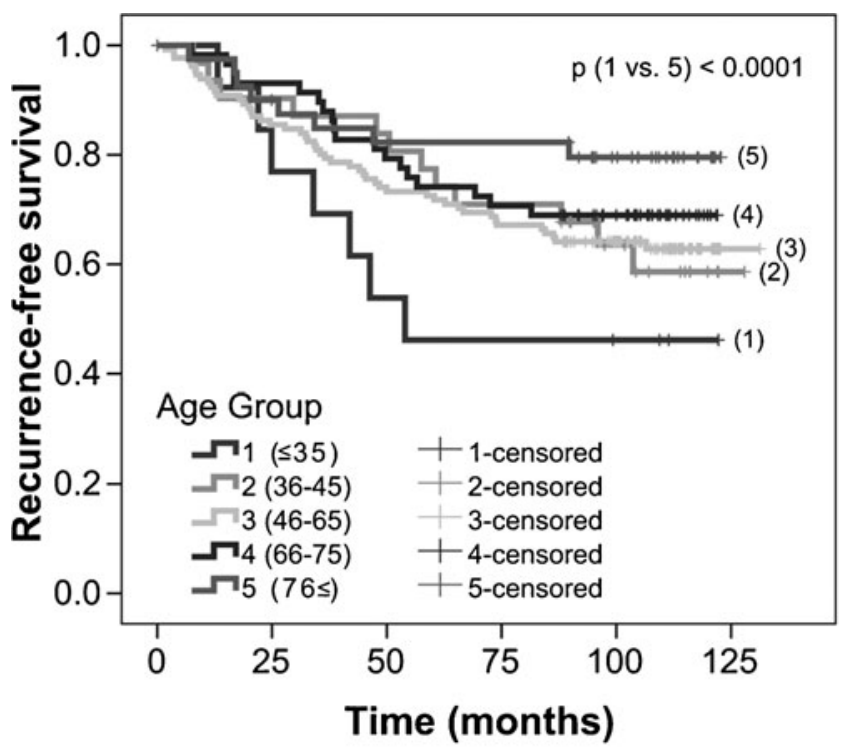

Fig. 3 The early-onset group displayed the worse prognosis when compared with the other groups the therapeutic strategies, although there was a tendency showing benefit for neoadjuvant therapy.

In 15 cases, PABC was diagnosed. No significant differences were detected in OS when comparing the PABC with the other group of young patients (Fig. 4d).

\section{Discussion}

According to literature data, younger patients affected by breast carcinoma have poor outcome $[6,20,21]$. There are increasing efforts to identify the group of patients considered high risk with higher specificity and sensitivity and there are serious debates regarding the factors responsible for breast cancer development at young age.

Breast cancer risk in females is increased in case of having either a first degree relative with breast or ovarian carcinoma, or having more than one relative affected by this disease $[22,23]$. The Cancer Collaborative Group on Hormonal Factors in Breast Cancer (CGoHFiB) has estimated the cumulative incidence of breast cancer up to the age of 80 for patients with various numbers of first degree relatives with the following cumulative incidence results: $7.8 \%$ for patients with no affected family, $13.3 \%$ with one first degree relative and $21.1 \%$ for patients with two first degree relatives [23].

In our study, by analysing the cases where the family history was reported we found that in $51.02 \%$ of the cases a family history of breast or ovarian carcinoma was reported in first and second degree relatives. This high prevalence of positive family history of breast and ovarian carcinoma highlights a considerable contribution of genetic factors to early-onset breast cancer. Similar results were described by Loman et al. in 2001 by analysing family history of breast and ovarian cancers in the Swedish population. They found that almost half of the women with early-onset breast cancer had a family history of breast or ovarian cancer. They also found that $9 \%$ of early-onset breast cancer cases are associated with germline mutation in the BRCA1 or BRCA2 genes [24].

Recent results of Evans et al. showed that few mutations were found in young women $(<35)$ without family history, demonstrating the importance of accurate documentation of the affected family members. Their study also pointed out that among sporadic breast cancer patients mutations are generally present in grade III cases and TNBCs [25].

In our study we found a high incidence of grade III tumours, while only four cases were considered as grade I tumour. According to the immunophenotypical results, which were available in 99 patients, 22 tumours were enrolled in LumA (22.22\%), 35 in LumB (35.35\%), 9 in HER2+ $(9.09 \%)$ and 33 in TNBC (33.33\%) subgroups. 
Fig. 4 No significant association between OS and negative family history versus a family history of breast or ovarian carcinoma in first and second degree relatives was detected (a). Survival of young breast cancer patients with negative family history versus positive family history of any tumour type other than breast carcinoma $(p=0.188)(\mathbf{b})$. No significant differences in survival $(p=0.188)$ were detectable between the applied therapies (neoadjuvant chemotherapy or adjuvant chemotherapy), although there was a tendency showing benefit of neoadjuvant therapy (c). No significant differences were detected in OS when comparing the PABC with the other group of young patients (d) a

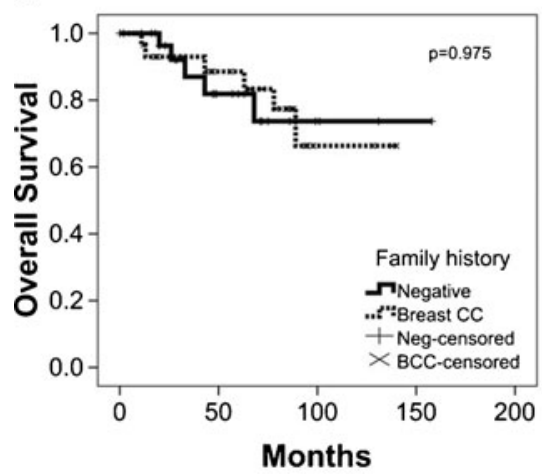

C

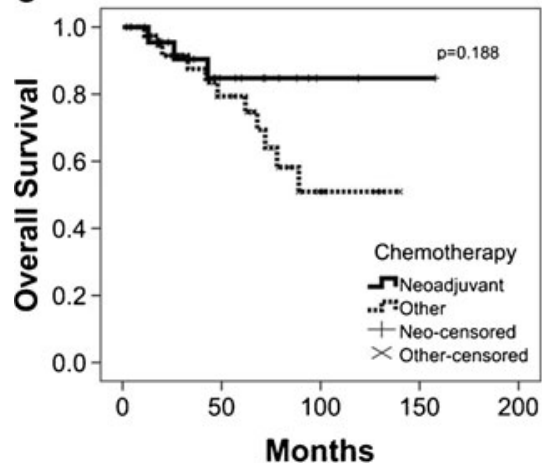

b

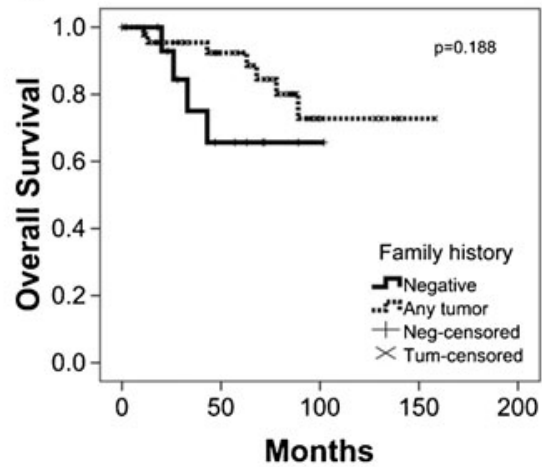

d

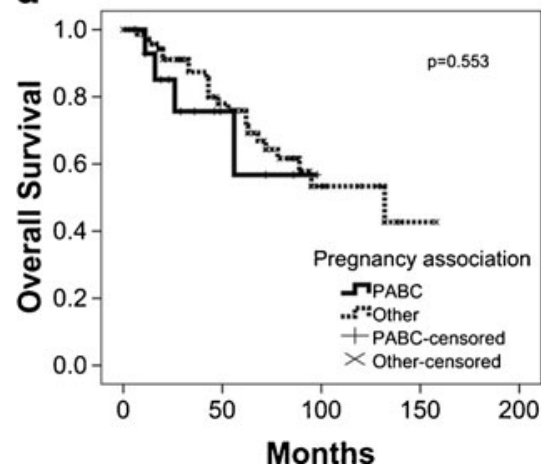

Patients with family history of breast or ovarian carcinomas were represented by increased proportion (52\%) among TNBC breast carcinoma cases when compared with the group of patients without family history of breast and ovarian carcinoma where the LumA tumours were found in higher percentage $(46.15 \%)$. In a very recent study by Jiang et al. by analysing a heterogenous population diagnosed with breast carcinomas it was found that in cancers diagnosed before the age of 50, women with a family history of breast cancer are more likely to have ER negative and PgR negative tumours compared to women without family history [26]. This information highlights the necessity of more detailed analyses of the family history especially in patients of younger age.

In 2011, van der Hage et al. found that for young patients, molecular subtype, tumour size and nodal status were independent prognostic factors for overall survival. They also mentioned that in their group consisting of 341 nodenegative patients, patients with LumA tumours under 40 years of age had an overall survival rate of $94 \%$ at 10 years compared with patients presenting basal-like tumours with only $72 \%$ survival rate [27]. Another recent study found that breast cancer in younger women (less than 40 years of age) has distinct histopathological characteristics, but the authors did not find reduced survival in the younger patient group as compared with the group consisting of patients over 40 [28]. It is controversial how this differences present between breast carcinomas arising at the extremes age are explained. Anders et al. suggest that these differences are strongly influenced by genes associated with intrinsic breast cancer subtype and grade both of which beeing correlated with age[29]. In an earlier study of Anders et al. it is presented that breast cancer arising in young women clearly represents a distinct biologic entity and is characterized by specific signaling pathway[30].

In our study, at the time of analysis $23.36 \%$ of young BC patients died. An approximately similar high percentage of deaths was reported by van der Hage et al. in their study group consisting of patients less than 40 years of age [27]. The Korean Breast Cancer Society reported that young age was associated with a greater probability of death in breast cancer patients [31]. Upon analysing tumour subtypes in the group of patients who died we found that of the 25 patients, the highest number of deaths was observed in the LumB subgroup, followed by the TNBC subgroup, LumA subgroup and HER2+ subgroup.

We did not find significant association between OS and negative family history versus a family history of breast or ovarian carcinoma in first and second degree relatives. No significant differences in OS were detectable between the applied (neoadjuvant and adjuvant chemotherapy) regimens either.

The results presented in this study provide further negative data about breast cancer survival in relation to young age. We have found that breast cancer arising in young women is characterised by the presence of less favorable subtypes such 
TNBC and LumB. The increased proportion of TNBC was especially remarquable in the group of patients with a family history of the disease. The fact that a high rate of death occured irrespective of the applied therapies used suggests that new and more specific treatment guidelines should be developed in this patient group.

Acknowledgments We are grateful to the patients who consented to participate in this study. Authors are also grateful to Mrs Elvira KaleRigo for the careful reading of our manuscript and to Erzsebet Azumah, Magdolna Pekár and Erika Samodai for their contribution to immunohistochemical analyses and FISH procedures.

This study was supported by the following grants: ETT-088-01/2009, MKOT-GSK/2008, MKOT-Roche/2010, TÁMOP-4.2.1.B-09/1/KMR2010-0001, TÁMOP-4.2.2/B-10/1-2010-0013, and MTA-2012TKI643.

\section{References}

1. Tusnady G, Gaudi I, Rejto L, Kasler M, Szentirmay Z (2008) Survival chances of hungarian cancer patients in the national cancer registry. Magy Onkol 52:339-349

2. American Cancer Society Workshop on Breast Cancer Detection in Younger Women (1993) A current assessment. Proceedings. New York, February 1-2, 1993. Cancer 72(4 suppl):1428-1497

3. Paluch-Shimon S, Wolf I, Sadetzki S, Gluck I, Oberman B et al (2011) Association between very young age and adverse characteristics of breast cancer at presentation amongst Israeli women. Am J Clin Oncol 34:219-222

4. Nixon AJ, Neuberg D, Hayes DF, Gelman R, Connolly JL et al (1994) Relationship of patient age to pathologic features of the tumor and prognosis for patients with stage I or II breast cancer. J Clin Oncol 12:888-894

5. Fredholm H, Eaker S, Frisell J, Holmberg L, Fredriksson I et al (2009) Breast cancer in young women: poor survival despite intensive treatment. PLoS One 4:e7695

6. Aebi S, Gelber S, Castiglione-Gertsch M, Gelber RD, Collins J et al (2000) Is chemotherapy alone adequate for young women with oestrogen-receptor-positive breast cancer? Lancet 355:1869-1874

7. Kim K, Chie EK, Han W, Noh DY, Oh DY et al (2011) Age $<40$ Years is an independent prognostic factor predicting inferior overall survival in patients treated with breast conservative therapy. Breast J 17:75-78

8. Bonnier P, Romain S, Charpin C, Lejeune C, Tubiana $\mathrm{N}$ et al (1995) Age as a prognostic factor in breast cancer: relationship to pathologic and biologic features. Int J Cancer 62:138-144

9. Colleoni M, Rotmensz N, Robertson C, Orlando L, Viale G et al (2002) Very young women ( $<35$ years) with operable breast cancer: features of disease at presentation. Ann Oncol 13:273-279

10. Lin CH, Lu YS, Huang CS, Kuo KT, Wang CC et al (2011) Prognostic molecular markers in women aged 35 years or younger with breast cancer: is there a difference from the older patients? J Clin Pathol 64:781-787

11. Abenhaim HA, Azoulay L, Holcroft CA, Bure LA, Assayag J et al (2012) Incidence, risk factors, and obstetrical outcomes of women with breast cancer in pregnancy. Breast J 18:564-568

12. Chun J, Pocock B, Joseph KA, El-Tamer M, Klein L et al (2009) Breast cancer risk factors in younger and older women. Ann Surg Oncol 16:96-99

13. Ford D, Easton DF, Stratton M, Narod S, Goldgar D et al (1998) Genetic heterogeneity and penetrance analysis of the BRCA1 and BRCA2 genes in breast cancer families. The Breast Cancer Linkage Consortium. Am J Hum Genet 62:676-689
14. Van Der Looij M, Szabo C, Besznyak I, Liszka G, Csokay B et al (2000) Prevalence of founder BRCA1 and BRCA2 mutations among breast and ovarian cancer patients in Hungary. Int J Cancer 86:737-740

15. Antoniou AC, Hardy R, Walker L, Evans DG, Shenton A et al (2008) Predicting the likelihood of carrying a BRCA1 or BRCA2 mutation: validation of BOADICEA, BRCAPRO, IBIS, Myriad and the Manchester scoring system using data from UK genetics clinics. J Med Genet 45:425-431

16. Berry DA, Iversen ES Jr, Gudbjartsson DF, Hiller EH, Garber JE et al (2002) BRCAPRO validation, sensitivity of genetic testing of BRCA1/BRCA2, and prevalence of other breast cancer susceptibility genes. J Clin Oncol 20:2701-2712

17. van Harssel JJ, van Roozendaal CE, Detisch Y, Brandao RD, Paulussen AD et al (2010) Efficiency of BRCAPRO and Myriad II mutation probability thresholds versus cancer history criteria alone for BRCA1/2 mutation detection. Fam Cancer 9:193-201

18. Hickey M, Peate M, Saunders CM, Friedlander M (2009) Breast cancer in young women and its impact on reproductive function. Hum Reprod Update 15:323-339

19. Gaudet MM, Press MF, Haile RW, Lynch CF, Glaser SL, et al. (2011) Risk factors by molecular subtypes of breast cancer across a population-based study of women 56 years or younger. Breast Cancer Res Treat 130:587-597

20. Han W, Kim SW, Park IA, Kang D, Youn YK et al (2004) Young age: an independent risk factor for disease-free survival in women with operable breast cancer. BMC Cancer 4:82

21. Fodor J, Mozsa E, Zaka Z, Polgar C, Major T (2005) Local relapse in young $(<$ or $=40$ years $)$ women with breast cancer after mastectomy or breast conserving surgery: 15-year results. Magy Onkol 49:205-208, 203

22. Claus EB, Risch NJ, Thompson WD (1990) Age at onset as an indicator of familial risk of breast cancer. Am J Epidemiol 131:961-972

23. Collaborative Group of Hormonal Factors in Breast Cancer (2001) Familial breast cancer: collaborative reanalysis of individual data from 52 epidemiological studies including 58,209 women with breast cancer and 101,986 women without the disease. Lancet 358:1389-1399

24. Loman N, Johannsson O, Kristoffersson U, Olsson H, Borg A (2001) Family history of breast and ovarian cancers and BRCA1 and BRCA2 mutations in a population-based series of early-onset breast cancer. J Natl Cancer Inst 93:1215-1223

25. Evans DG, Howell A, Ward D, Lalloo F, Jones JL et al (2011) Prevalence of BRCA1 and BRCA2 mutations in triple negative breast cancer. J Med Genet 48:520-522

26. Jiang X, Castelao JE, Chavez-Uribe E, Fernandez Rodriguez B, Celeiro Munoz C et al (2012) Family history and breast cancer hormone receptor status in a Spanish cohort. PLoS One 7:e29459

27. van der Hage JA, Mieog JS, van de Velde CJ, Putter H, Bartelink H et al (2011) Impact of established prognostic factors and molecular subtype in very young breast cancer patients: pooled analysis of four EORTC randomized controlled trials. Breast Cancer Res 13:R68

28. Kheirelseid EA, Boggs JM, Curran C, Glynn RW, Dooley C et al (2011) Younger age as a prognostic indicator in breast cancer: a cohort study. BMC Cancer 11:383

29. Anders CK, Fan C, Parker JS, Carey LA, Blackwell KL et al (2011) Breast carcinomas arising at a young age: unique biology or a surrogate for aggressive intrinsic subtypes? J Clin Oncol 29:e18-e20

30. Anders CK, Hsu DS, Broadwater G, Acharya CR, Foekens JA et al (2008) Young age at diagnosis correlates with worse prognosis and defines a subset of breast cancers with shared patterns of gene expression. J Clin Oncol 26:3324-3330

31. Ahn SH, Son BH, Kim SW, Kim SI, Jeong J et al (2007) Poor outcome of hormone receptor-positive breast cancer at very young age is due to tamoxifen resistance: nationwide survival data in Korea-a report from the Korean Breast Cancer Society. J Clin Oncol 25:2360-2368 